\title{
Topographic Science
}

The mission of U.S. Geological Survey (USGS) Earth Resources Observation and Science (EROS) Center Topographic Science is to establish partnerships and conduct research and applications that facilitate the development and use of integrated national and global topographic datasets. Topographic Science includes a wide range of research and applications that result in improved seamless topographic datasets, advanced elevation technology, data integration and terrain visualization, new and improved elevation derivatives, and development of Web-based tools. In cooperation with our partners, Topographic Science is developing integrated-science applications for mapping, national natural resource initiatives, hazards, and global change science. http://topotools.cr.usgs. gov/.

\section{National Elevation Dataset}

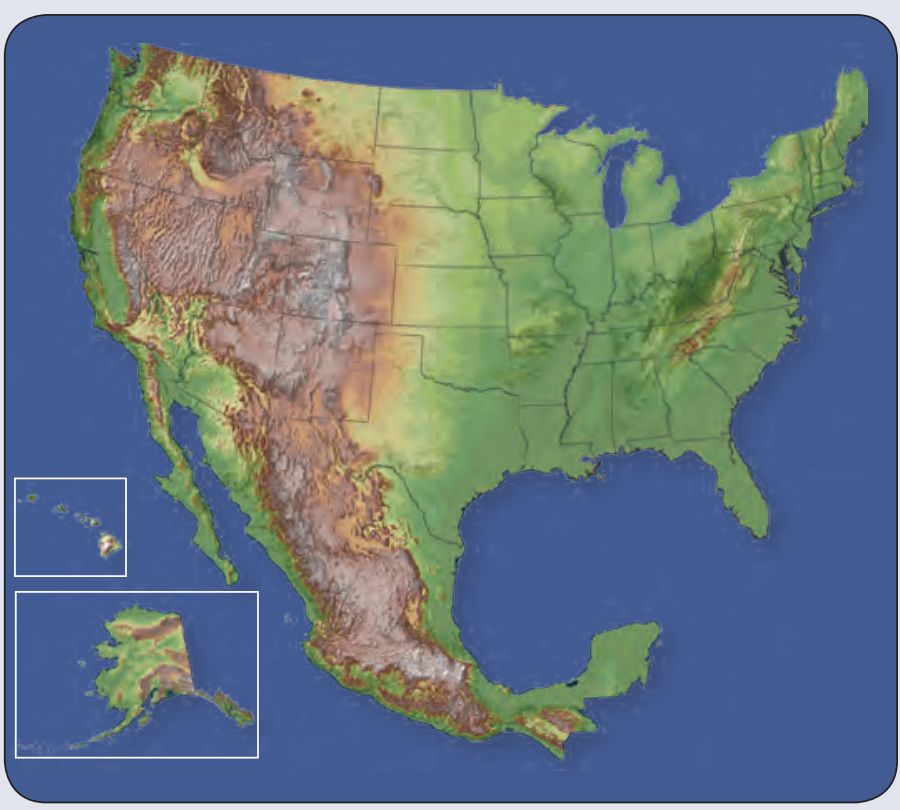

Shaded relief images of the National Elevation Dataset.

The National Elevation Dataset (NED) is produced and distributed by the USGS. The NED includes data for the United States and Mexico, and serves as the elevation layer of The National Map. The NED became available in 1999 at a 30-meter resolution. Since 2003, the NED has evolved into a multi-resolution dataset that provides the best available elevation data, including 3-meter or better light detection and ranging (lidar) data. Scientists, resource managers, and educators use NED data for global change research, hydrologic modeling, resource monitoring, mapping and visualization, and many other applications. Additional information regarding
NED is available at http://ned.usgs.gov/. The National Map-Elevation fact sheet is available at http://pubs.usgs.gov/ $f_{S} / 2009 / 3053 /$.

Gesch, D.B., 2007, Chapter 4 - The National Elevation Dataset, in Maune, D.F., ed., Digital elevation model technologies and applications-The DEM Users Manual ( $2 \mathrm{~d}$ ed.): Bethesda, Maryland, American Society for Photogrammetry and Remote Sensing, p. 99-118.

\section{Topographic Change}

The USGS has developed a national inventory of significant topographic changes based on seamless multitemporal elevation data and land cover data. The NED and the Shuttle Radar Topography Mission (SRTM) data form a unique pair of seamless elevation datasets that can be used to detect and analyze 20th century topographic surface changes in the United States. The need for more comprehensive information on the nature and extent of recent human geomorphic activity led to a spatial emphasis for the first ever accounting of topographic change across the United States. The primary types of

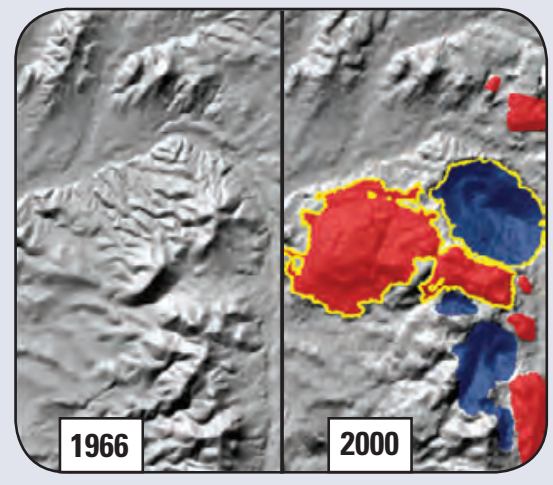

Topographic change in a gold mining operation near Carlin in north central Nevada. The left image is NED shaded relief and the right image is SRTM shaded relief with change polygons overlaid (blue = cut; red $=$ fill).

topographic changes resulting from human geomorphic activity include surface mining, road construction, urban development, dam construction, and landfills. Additional information is available online at http://topochange.cr.usgs.gov/.

Gesch, D.B., 2005, Analysis of multi-temporal geospatial data sets to assess the landscape effects of surface mining, in Barnhisel, R.I., ed., Proceedings, 22nd Annual National Conference of the American Society of Mining and Reclamation, Breckenridge, Colorado, June 19-23, 2005 (CD-ROM), ASMR, Lexington, Kentucky, p. 415-432. 


\section{Center for Lidar Information Coordination and Knowledge}

There has been an increasing demand for research utilizing all information generated from lidar remote sensing data. Although this technology has been a proven mapping tool, effective for generating bare earth digital elevation models (DEMs), research on using the entire point cloud of this remote sensing data for scientific applications has been slowed by the cost of collecting lidar, and a steep learning curve on research and understanding involving utilizing the entire point cloud. The goal of the USGS Center for Lidar Information Coordination and Knowledge (CLICK) is to facilitate data access, user coordination, and education of lidar remote sensing for scientific needs. Additional information is available online at http://lidar.cr.usgs.gov/.

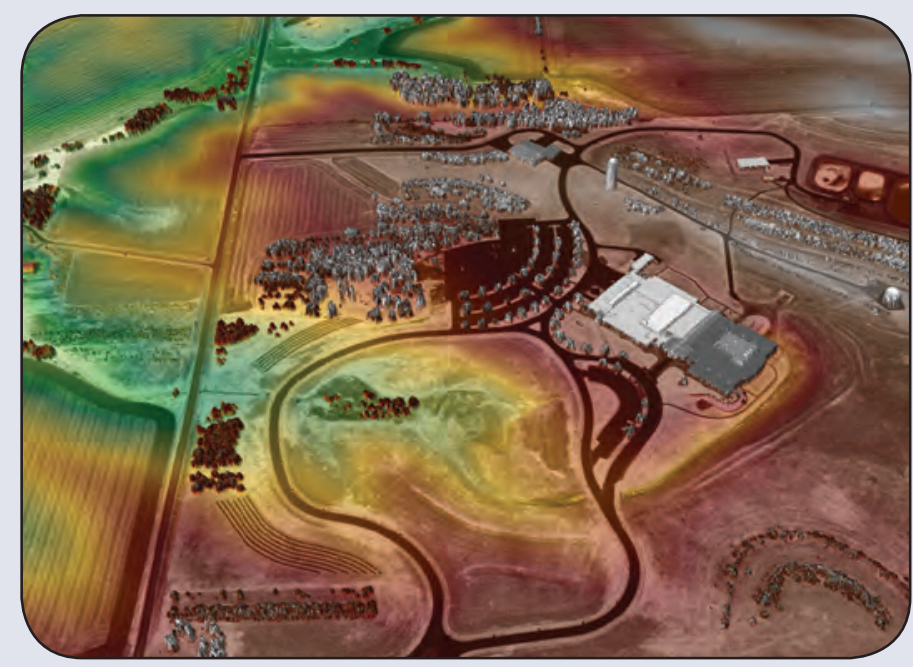

Light detection and ranging intensity and elevation models for the USGS EROS, Sioux Falls, South Dakota.

Stoker, J.M., Greenlee, S.K., Gesch, D.B., and Menig, J.C., 2006, CLICK-The New USGS Center for Lidar Information Coordination and Knowledge: Photogrammetric Engineering \& Remote Sensing, v. 72, p. 613-616.

\section{Lidar Vegetation Research}

Forests serve as a primary reservoir of terrestrial carbon. To better understand the carbon cycles of terrestrial ecosystems, scientists need accurate estimates of biomass. With this knowledge, the sources and sinks of carbon that result from converting a forest to cleared land can be calculated and vice versa. Lidar can directly measure vegetation structure and provide a better estimation of forest above-ground biomass compared to optical sensors that suffer from saturation in spectral response from dense canopies with high biomass. Forest information that can be directly retrieved from lidar data includes canopy height, sub-canopy topography, and vertical distributions of canopies. Lidar remote sensing can provide horizontal and vertical information, depending on the type of lidar system used and its configuration. Examples of lidar systems include discrete return or full waveform lidar.
Stoker, J., 2009, Volumetric visualization of multiple-return lidar data-Using voxels: Photogrammetric Engineering and Remote Sensing, v. 75, p. 109-112.

\section{Advanced Lidar Sensor Research}

The lidar sensor of tomorrow likely will be fundamentally different from the lidar sensor of today. Whereas the ranging, pointing, and positioning components will be inherent in a lidar instrument, the information contained in a lidar signal will undoubtedly evolve. Satellite-based lidar platforms are dramatically different from today's commercial sensor. New types of lidar sensors are in the development process, such as waveform-resolving lidars, photon-counting lidars, and flashimaging lidars. These sensors produce data that are completely different from discrete-return point cloud data. To continue to be the leader in lidar research and operations, USGS is conducting investigations of evolving lidar technology.

Tan, S., Stoker, J.M., Greenlee, S.K., 2008, Detection of foliage-obscured vehicle using a multiwavelength polarimetric LIDAR, in International Geoscience and Remote Sensing Symposium, Barcelona, July 23-27, 2007, Proceedings: Piscataway, New Jersey, IEEE, p. 2,503-2,506.

\section{Terrestrial Lidar Research}

Terrestrial lidar, also known as ground-based laser scanning, is a technology used for mapping land cover and man-made structures at a resolution of 2 centimeters. Terrestrial lidar scanning of certain landforms or structures produces georeferenced three-dimensional elevation data at centimeter scale. These dense lidar scans are used to quantify slope deposition, vegetation structure, nesting habitat of cliff dwelling birds, and beach morphology. Research applications include determining the accuracy of aerial lidar along shorelines and wetlands. Using terrestrial lidar to determine the accuracy of topographic data in coastal areas will aid in creating sea-level rise models.

\section{Coastal Vulnerability to Sea Level Rise}

The importance of sea-level rise in shaping coastal landscapes is well known within the earth science community. However, determining the potential environmental and socioeconomic impacts of sea-level rise, and communicating the associated risks, remains a challenge. Topography is a key parameter that influences many of the processes involved in

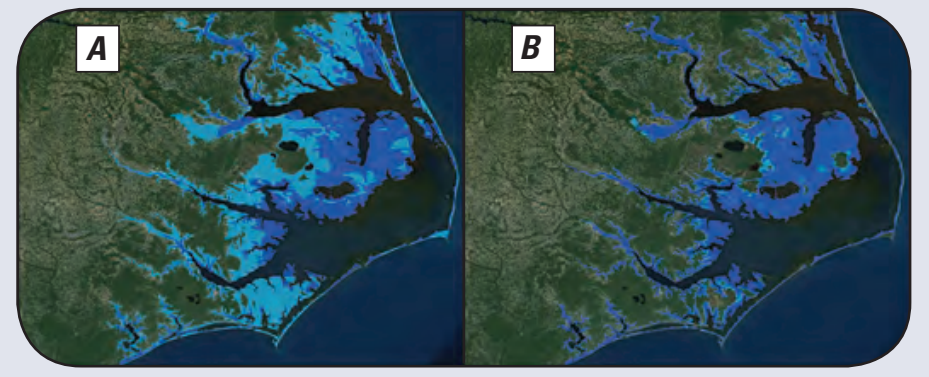

Maps of lands vulnerable to sea-level rise, derived from $(A) 1$ arcsecond NED (USGS 30 meter DEM source), and (B) 1/9 arc-second NED (lidar source). 
coastal change, and thus, recent, high-resolution, high-accuracy elevation data are required to model the coastal environment.

Maps of lands vulnerable to sea-level rise have been produced based on coastal elevation data, although these maps are quite limited in usefulness because they are derived from older, coarse elevation data. Recently, high quality elevation data derived from lidar have become available for many coastal areas. With high vertical accuracy and spatial resolution, these lidar data are an excellent source of topographic information from which improved maps of lands vulnerable to sea-level rise can be produced.

Gesch, D.B., 2009, Analysis of lidar elevation data for improved identification and delineation of lands vulnerable to sea level rise: Journal of Coastal Research, SI, no. 53, p. 49-58.

\section{Topographic-Bathymetric Data}

Topographic-bathymetric data, also known as topobathy data, are a merged rendering of topography (land elevation) and bathymetry (water depth) to provide a single product useful for inundation mapping and a variety of other applications. Topography was obtained from the USGS NED. Bathymetry was provided by National Oceanic and Atmospheric Administration (NOAA) GEOphysical DAta System (GEODAS). Northern Gulf of Mexico topobathy data are being

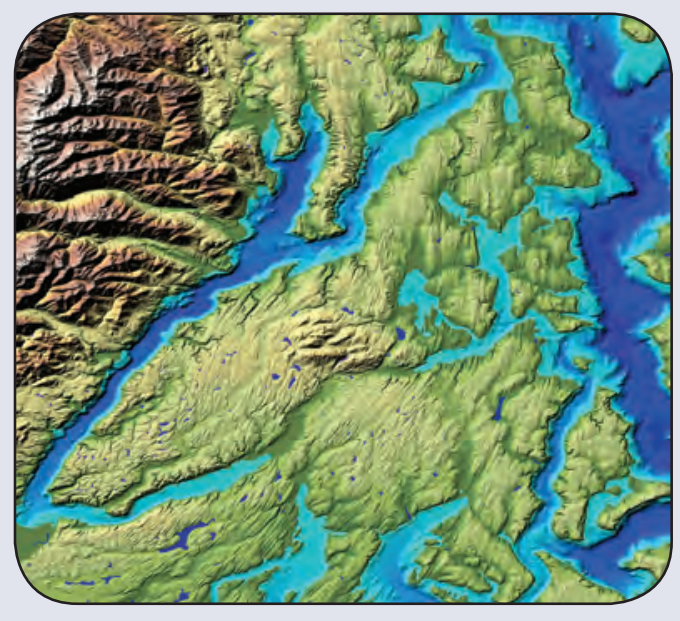

Topobathy data for Puget Sound, Washington.

developed in collaboration with the USGS Coastal and Marine Geology Program. Additional information is available at http:// topotools.cr.usgs.gov/topobathy_viewer/.

Tyler, D., Zawada, D.G., Nayegandhi, A., Brock, J.C., Crane, M.P., Yates, K.K., and Smith, K.E.L., 2007, Topobathymetric Data for Tampa Bay, Florida: U.S. Geological Survey OpenFile Report 2007-1051 (revised).

\section{Elevation Derivatives for National Applications}

Elevation Derivatives for National Applications (EDNA) is a multi-layered database derived from a version of the NED that has been hydrologically conditioned for improved hydrologic flow representation. The seamless EDNA database provides 30-meter resolution raster and vector data layers. Hydrologically conditioned elevation data, systematically and consistently processed to create hydrologic derivatives, can be useful in many topologically based visualization and investigative applications. Drainage areas upstream

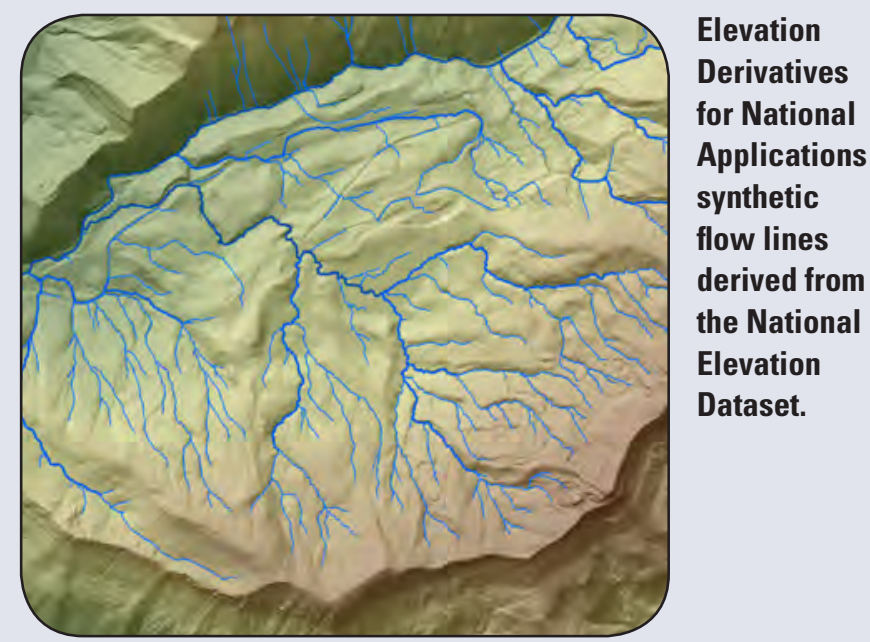

or downstream from any location can be accurately traced facilitating flood analysis investigations, pollution studies, and hydroelectric power generation projects. Additional information is available at http://edna.usgs.gov/.

Franken, S.K., Tyler, D.J., and Verdin, K.L., 2001, Development of a National seamless database of topography and hydrologic derivatives, Proceedings: 21 st ESRI User's Conference, July 9-13, 2001, San Diego, California.

\section{Lidar-derived surface flow}

Digital elevation data commonly are used to extract surface flow features. One source for high-resolution elevation information is lidar. Lidar can capture a vast amount of topographic detail because of its fine-scale ability to digitally capture the earth's surface. Because elevation is a key factor in extracting surface flow features, high-resolution lidar-derived DEMs provide the detail needed to consistently integrate hydrography with elevation, land cover, structures, and other geospatial features needed for water resource management. High-resolution lidar-derived DEMs provide the accuracy needed to systematically quantify and fully integrate surface flow including flow direction, flow accumulation, sinks, slope, and a dense drainage network.

Poppenga, S.K., Worstell, B.B., Stoker, J.M., and Greenlee, S.K., 2010, Using selective drainage methods to extract continuous surface flow from 1-meter lidar-derived digital elevation data: U.S. Geological Survey Scientific Investigations Report 2010-5059, 12 p.

\section{Multi-Hazards Debris Flow Inundation Tool}

Topographic Science in collaboration with the MultiHazards Demonstration Project for southern California developed geospatial tools and datasets for mapping raininduced debris flow events. The Lahar Inundation Hazard Zones (LAHARZ) tool for mapping volcanic lahar inundation was modified to work using a geoprocessing environment with revised model equations and newly acquired lidar-based DEM data. The new tools provide the capability to build database repositories of DEM derivatives and derive inundation zones for specified debris flow volumes. 


\section{GTOP030}

GTOPO30 is a global DEM with a horizontal grid spacing of 30 arc-seconds (approximately 1 kilometer). GTOPO30 was derived from several raster and vector sources of topographic information. GTOPO30 has been used extensively for regional, continental, and global studies of Earth-surface processes and for numerous global change applications. Additional information is available at http://eros.usgs.gov/\#/Find_Data/ Products_and_Data_Available/gtopo30_info.

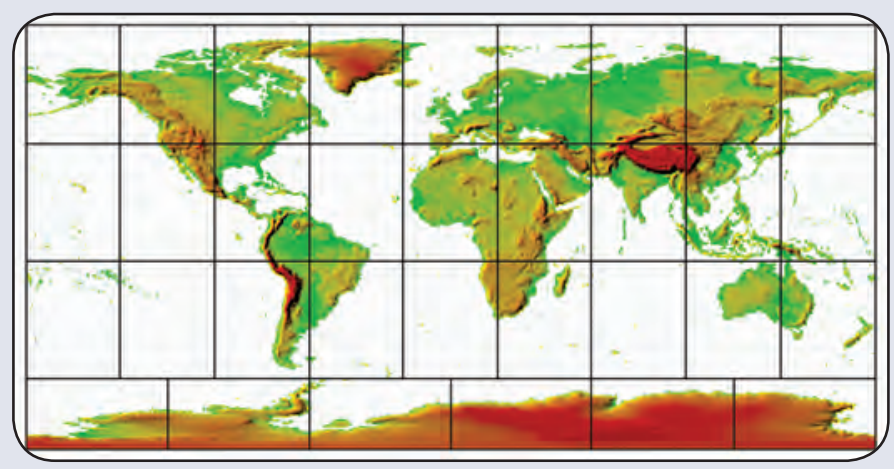

A map of the GTOP030 global digital elevation model.

Gesch, D.B., Verdin, K.L., and Greenlee, S.K., 1999, New land surface digital elevation model covers the earth: Eos, Transactions, American Geophysical Union, v. 80, no. 6, p. 69-70.

\section{Enhanced Global Elevation Model}

The USGS and the National Geospatial-Intelligence Agency (NGA) have collaborated on the development of a notably enhanced global elevation model called the Global Multi-resolution Terrain Elevation Data (GMTED2010), which will replace GTOPO30 as the elevation dataset of choice for global and continental scale applications. The new model has been generated at three separate resolutions of 30 arc-seconds, 15 arc-seconds, and 7.5 arc-seconds. An additional advantage of this new multi-resolution global model is that seven new raster elevation products will be available at each resolution. The new elevation products are being produced using the following aggregation methods: minimum elevation, maximum elevation, mean elevation, median elevation, standard deviation of elevation, systematic subsample, and breakline emphasis. The primary source dataset for the new global model is the SRTM 1 arc-second data.

Danielson, J.J., and Gesch, D.B., 2008, An enhanced global elevation model generalized from multiple higher resolution source datasets: The International Archives of the Photogrammetry, Remote Sensing, and Spatial Information Sciences, v. XXXVII, Part B4, p. 1,857-1,863.

\section{SSURGO Analysis by USGS/EROS for USEPA}

The USGS provides custom analyses of the Soil Survey Geographic (SSURGO) detailed soil data for the conterminous United States in support of the U.S. Environmental Protection Agency (USEPA) Atlas of Environmental Services. The
SSURGO data were developed and maintained by the U.S. Department of Agriculture Natural Resources Conservation Service (NRCS). The collaboration between USEPA and USGS includes technical exchanges with NRCS staff. Although the primary focus of this effort uses SSURGO data, other datasets are incorporated in the analyses where appropriate, such as the NED, the National Land Cover Dataset, and appropriate boundary datasets.

Sundquist, E.T., Ackerman, K.V., Bliss, N.B., Kellndorfer, J.M., Reeves, M.C., and Rollins, M.G., 2009, Rapid assessment of U.S. forest and soil organic carbon storage and forest biomass carbon sequestration capacity: U.S. Geological Survey OpenFile Report 2009-1283, 15 p.

\section{FAA Web Service}

In accordance with an agreement with the Federal Aviation Administration (FAA), an FAA Web service was implemented. The FAA uploads a polygon to the Web service, and the Web service returns the $\mathrm{x}, \mathrm{y}, \mathrm{z}$ values of the highest elevation point in the polygon. This information is used with their obstructions database to feed a component of their airport approach planning model. In the course of deploying this model, several erroneous data points were discovered and corrected in the NED resulting in mutual benefit to FAA and USGS. The FAA Web service averages more than 1,300 requests per day. There have been as many as 500 requests in 2 hours.

Information about Topographic Science is available at:

http://topotools.cr.usgs.gov/

Or by contacting:

USGS EROS Center

Customer Services

Mundt Federal Building

Sioux Falls, SD 57198

Telephone: 605-594-6151

Fax: 605-594-6589

E-mail: custserv@usgs.gov

For information on other USGS products and services, call 1-888-ASK-USGS or visit the general interest publications Web site on mapping, geography, and related topics at erg.usgs.gov/isb/pubs/pubslists/.

For additional information, visit the ask.usgs. gov Web site or the USGS home page at http:// www.usgs.gov/.

Publishing support provided by: Rolla Publishing Service Center 